\title{
Phytophthora infestans Isolates Lacking Class I ipiO Variants Are Virulent on Rpi-blb1 Potato
}

\author{
Nicolas Champouret, ${ }^{1}$ Klaas Bouwmeester, ${ }^{2}$ Hendrik Rietman, ${ }^{1}$ Theo van der Lee, ${ }^{3}$ Chris Maliepaard, ${ }^{1}$ \\ Anika Heupink, ${ }^{1}$ Peter J. I. van de Vondervoort, ${ }^{2}$ Evert Jacobsen, ${ }^{1}$ Richard G. F. Visser, ${ }^{1}$ \\ Edwin A. G. van der Vossen, ${ }^{1}$ Francine Govers, ${ }^{2}$ and Vivianne G. A. A. Vleeshouwers ${ }^{1}$ \\ ${ }^{1}$ Wageningen UR Plant Breeding, P.O. Box 386, 6700 AJ, Wageningen, The Netherlands; ' 2 aboratory of Phytopathology,

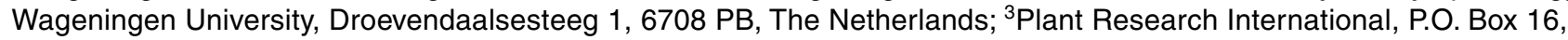 \\ 6700 AA Wageningen, The Netherlands
}

Submitted 23 April 2009. Accepted 15 July 2009.

\begin{abstract}
A strategy to control the devastating late blight disease is providing potato cultivars with genes that are effective in resistance to a broad spectrum of Phytophthora infestans isolates. Thus far, most late blight resistance $(R)$ genes that were introgressed in potato were quickly defeated. In contrast, the Rpi-blb1 gene originating from Solanum bulbocastanum has performed as an exclusive broad-spectrum $\boldsymbol{R}$ gene for many years. Recently, the RXLR effector family ipiO was identified to contain Avr-blb1. Monitoring the genetic diversity of the ipiO family in a large set of isolates of $P$. infestans and related species resulted in $16 \mathrm{ipiO}$ variants in three distinct classes. Class I and class II but not class III ipiO variants induce cell death when coinfiltrated with Rpi-blb1 in Nicotiana benthamiana. Class I is highly diverse and is represented in all analyzed $P$. infestans isolates except two Mexican $P$. infestans isolates, and these were found virulent on Rpi-blb1 plants. In its C-terminal domain, IPI-O contains a W motif that is essential for triggering Rpi-blb1-mediated cell death and is under positive selection. This study shows that profiling the variation of $A v r-$ blb1 within a $P$. infestans population is instrumental for predicting the effectiveness of Rpi-blb1-mediated resistance in potato.
\end{abstract}

Late blight caused by the oomycete Phytophthora infestans is one of the most severe threats to potato production worldwide (Fry 2008). Despite many efforts, effective methods to control late blight epidemics are still not available. In recent years, however, intensified research on both the pathogen and the host plant has deepened our insight into the molecular ba-

N. Champouret, K. Bouwmeester, and H. Rietman share first authorship and F. Govers, and V. G. A. A. Vleeshouwers share last authorship.

Current address for Peter J. I. van de Vondervoort: DSM Food Specialties, P.O. Box 1, 2600 MA Delft, The Netherlands.

Current address for Edwin A. G. van der Vossen: Keygene N.V., Agro Business Park 90, 6708 PW, Wageningen, The Netherlands.

Corresponding author: Vivianne G. A. A. Vleeshouwers;

E-mail: Vivianne.Vleeshouwers@wur.nl

DNA sequence data is available in the NCBI GenBank database under the accession numbers GQ371190 through GQ371203.

* The $e$-Xtra logo stands for "electronic extra" and indicates that four supplemental figures and four supplemental tables are published online. Also, Figure 5 appears in color online. sis of virulence and avirulence determinants in $P$. infestans and of host defense responses. This knowledge is instrumental in obtaining genetic resistance in potato (Bryan and Hein 2008; Govers and Gijzen 2006; Park et al. 2009).

In order to invade plant cells without hindrance, pathogens secrete effector proteins that can manipulate host defense responses, thus resulting in effector-triggered susceptibility (ETS) (Jones and Dangl 2006; Kamoun 2006, 2007). When an effector is recognized by a resistance $(\mathrm{R})$ protein, effector triggered immunity (ETI) is activated, often resulting in a hypersensitive response (HR). Effectors then act as avirulence (Avr) factors and the encoding $A v r$ genes interact with $R$ genes according to the gene-for-gene model (Flor 1971). The molecular arms race between the pathogen and its host drives coevolution of $R$-Avr gene pairs, as has been clearly demonstrated with the Arabidopsis $R$ gene $R P P 13$ and the corresponding Avr factor ATR13 of the oomycete Hyaloperonospora arabidopsidis (formerly $H$. parasitica) (Allen et al. 2004). Both RPPl3 and $A T R 13$ are highly variable, and by examining natural variants of ATR13, key amino acids were identified that are functionally essential for interaction with RPP13 (Allen et al. 2008). In $P$. infestans, only a few Avr genes have so far been studied at the molecular level. Avr3a, the counterpart of the Solanum demissum gene $R 3 a$, has two alleles - a virulent one and an avirulent one - that differ only two amino acids (Armstrong et al. 2005). The latter, $A v r 3 a^{K I}$, not only triggers a $R 3 a$-dependent HR, it is also able to suppress a cell-death response induced by the elicitin INF1. These two activities, however, are conditioned by distinct amino acids (Bos et al. 2009). On the plant side, $R 3 a$ unleashed its evolutionary potential with numerous $R 3 a$-like genes, which resulted in a major late blight locus on chromosome 11 of Solanum demissum (Friedman and Baker 2007; Huang 2005; Huang et al. 2005). Avr4, which interacts with $S$. demissum $R 4$, has one predominant avirulent allele in nature but, unlike $A v r 3 a$, the virulent allele has frameshift mutations and can no longer produce an effector protein (van Poppel et al. 2008). Recently, we described the identification of another potential P. infestans Avr gene, i.e., $i p i O$, the in planta-induced gene that was postulated as being involved in pathogenicity based on its expression profile (van West et al. 1998). The identification of ipiO as Avr-blbl resulted from an effector genomics approach that is based on high throughput functional profiling of effector genes in plants carrying $R$ genes (Vleeshouwers et al. 2008). In the effector screening, two variants of $\mathrm{ipiO}$, i.e., ipiO1 and ipiO2, triggered a cell-death response in $S$. bulbocastanum plants carrying the late blight $R$ gene Rpi-blbl (alternatively named RB) (Song et 
al. 2003; van der Vossen et al. 2003; Vleeshouwers et al. 2008). Cell-death responses to ipiO1 and ipiO2 were also noted in S. stoloniferum, which is the source of the Rpi-blb1 homologs Rpi-stol and Rpi-ptal. Accordingly, agro-coinfiltration of Rpi-blb1, Rpi-stol, and Rpi-ptal with ipiO1 and ipiO2 in Nicotiana benthamiana resulted in specific cell death and provided functional evidence for the $R$-Avr interaction. However, ipiO4-a genetically more distant variant-did not elicit cell death when agro-coinfiltrated with Rpi-blbl nor with its homologs. This suggested that alleles or variants of the ipiO gene family vary with respect to recognition by Rpi-blbl and hence in avirulence to Rpi-blbl.

Like Avr3a and Avr4, IPI-O contains at its N-terminus a signal peptide for type II secretion and a RXLR-dEER motif for host-cell internalization, whereas the C-terminal domain is required for effector functions (Govers and Bouwmeester 2008; Rehmany et al. 2005; Whisson et al. 2007). The RXLR domain of IPI-O partly overlaps with a RGD cell adhesion motif, which has been shown to bind to a lectin receptor kinase in Arabidopsis that may function as an effector target (Gouget et al. 2006). This lectin receptor kinase participates in proteinprotein interactions to mediate cell wall-plasma membrane adhesions, and it has been observed that IPI-O can disrupt these adhesions (Senchou et al. 2004). In many of the RXLRdEER effectors, the C-terminal domain consists of a variable number of motifs that occur in a repeated fashion (Jiang et al. 2008). This allows rapid evolution and diversification within this effector family, which is consistent with a role for $A v r$ genes in gene-for-gene interactions with their hosts.

A wealth of $R$ genes is present in botanical Solanum species, but in spite of that, resistance breeding has thus far been unsuccessful. Introgressed $R$ genes from $S$. demissum and $S$. berthaultii, for example, were quickly defeated and virulent $P$. infestans isolates were detected in the field, sometimes even before introduction into cultivated potato (Flier et al. 2003; Grünwald et al. 2001; Rauscher et al. 2006; Wastie 1991). Recently, renewed hope for resistance breeding emerged with the identification of the so-called 'broad-spectrum' $R$ genes $R p i$ blb1 and Rpi-blb2 from S. bulbocastanum (Song et al. 2003; van der Vossen et al. 2003, 2005). Since the introduction in potato, Rpi-blbl appears to have remained effective in various geographical areas and over several growing seasons (Colton et al. 2006; Helgeson et al. 1998; Naess et al. 2000). The identification of $i p i O$ as the candidate for Avr-blbl enables us to address the question of how widespread avirulent alleles or variants occur in $P$. infestans populations and, related to this, how likely it is that Rpi-blb1-mediated resistance will last in the field. In this study, we monitored the genetic variation of $i p i O$ in a highly diverse set of $P$. infestans isolates and related Phytophthora species, and identified 16 naturally occurring $i p i O$ variants that could be grouped in three different classes. The $P$. infestans isolates lacking one specific class of $i p i O$ variants appeared to be virulent on plants carrying Rpi-blbl, thus confirming the gene-for-gene interaction between ipiO and Rpi-blbl. We also show that IPI-O contains a W motif in the C-terminal domain that is subject to positive selection and that this domain is sufficient to trigger Rpi-blbl-dependent cell death.

\section{RESULTS}

\section{The ipiO gene is highly diverse.}

For assessing natural genetic variation of ipiO, we compiled a set of $29 P$. infestans isolates that were collected from various geographic regions, including the European potatogrowing areas and the Central Highlands of Mexico that are both known to harbor genetically highly diverse $P$. infestans populations (Flier 2001; Flier et al. 2003; Rivera-Peña 1990a) (Supplementary Table 1). Furthermore, the P. infestans isolates originated from diverse host plants, including potato, tomato and botanical Solanum species, and they vary for year of collection, mating type, and virulence pattern on the potato $R 1-R 11$ differential set. To examine the genetic diversity, we fingerprinted $21 P$. infestans isolates with simple sequence repeat (SSR) markers and showed that nearly all isolates had a unique genotype. Only two isolates, i.e., IPO-0 and UK7824, had identical genotypes, and PRC505705 and PRC506303 have a highly similar genotype. No clear supported branching was observed upon neighbor joining in the cluster analysis, illustrating that the assembled set of $P$. infestans isolates is genetically highly diverse (Supplementary Fig. 1).

To determine the genetic variation at the $\mathrm{ipiO}$ loci, ipiO was amplified using polymerase chain reaction (PCR) on genomic DNA derived from the $29 P$. infestans isolates and from five isolates of other clade 1c species, i.e., $P$. andina, $P$. ipomoeae, $P$. phaseoli, and $P$. mirabilis (Blair et al. 2008). Sequence analyses revealed 16 variants of $i p i O$, with a minimum of one and a maximum of four ipiO variants per isolate (Table 1, Fig. 1, Supplementary Fig. 2). So far, no ipiO homologs have been detected in Phytophthora species outside clade 1c (data not shown). As described previously, IPI-O1 and IPI-O2 are highly similar, with only four different amino acids (Pieterse et al. 1994). Most of the newly identified IPI-O variants have amino-acid changes due to point mutations, i.e., IPI-O3 to IPIO9, IPI-O11, IPI-Om1, and IPI-Om2. IPI-O10 is identical to IPI-O2, although this variant contains two nonsynonymous nucleotide polymorphisms. Another variant, IPI-O13, has a Cterminal extension of 10 amino acids compared with IPI-O3. $P$. infestans variant IPI-O12 and $P$. phaseoli IPI-Op1 have frameshift mutations that result in truncated proteins.

Phylogenetic analyses on the protein alignment of the 16 IPI-O variants showed a grouping into three classes, designated as classes I, II, and III (Fig. 2). Phylogenetic trees based on neighbor-joining, minimal evolution, or maximum parsimony algorithms resulted in similar clustering (not shown), and analyses based on nucleotide alignments also yielded comparable results. Most IPI-O variants group in class I together with IPI-O1 and IPI-O2. Class II is significantly different from class I and includes IPI-O3 and IPI-O13. Class III comprises IPI-O4, which has 16 amino-acid differences compared with class I and II IPI-O variants and is the most divergent IPI-O variant in $P$. infestans.

IPI-O has one $W$ motif with several positively selected sites.

The majority of the RXLR-dEER effectors contain positively selected amino-acid residues in the $\mathrm{C}$-terminus (Jiang et al. 2008; Win et al. 2007). To investigate whether ipiO is also under diversifying selection, we assessed positive selection per residue on two sets of ipiO variants. The first set, called $\mathrm{Pi}$, is composed of the 11 full-length $i p i O$ variants as found in $P$. infestans. The other set, $\mathrm{Pi}+\mathrm{Pm}$, includes the variants detected in the sibling species $P$. mirabilis in addition to the Pi set. Of the different evolutionary models (Yang et al. 2005), model M2a for positive selection fits well on both data sets with $\ell$ values of -822.55 and -960.76 for $\mathrm{Pi}$ and $\mathrm{Pi}+\mathrm{Pm}$, respectively. With this model, several positively selected amino-acid residues were identified, four of which overlap in the two data sets. Also the selection model M8 gave high log likelihood values for both sets. For the Pi set, M2a and M8 identified the same seven positively selected sites. For the $\mathrm{Pi}+\mathrm{Pm}$ set, M8 identified the same set of four overlapping positively selected sites and four additional ones, one of which is also selected by the M2a model for the Pi+Pm set (Table 2). 
In a recent study that used hidden Markov model (HMM) searches to find motifs in RXLR-dEER effectors, it was shown that many of the RXLR-dEER effectors contain conserved Cterminal motifs that may occur in repeated fashion (Jiang et al. 2008). These motifs were named $\mathrm{W}, \mathrm{Y}$, and L after the amino acid at a fixed position in each motif. IPI-O contains a single $\mathrm{W}$ motif with moderate to strong HMM scores ranging from 6.5 to 12.3 among the IPI-O variants (Fig. 1, Supplementary Fig. 3). Interestingly, three of the four positively selected sites that overlap in the M2a and M8 model of the two sets have a high posterior probability $(P>99 \%)$ and are located within the conserved W motif (Fig. 1).

\section{The region comprising the $\mathrm{W}$ motif is sufficient to trigger Rpi-blb1-mediated cell death.}

To investigate whether or not the $\mathrm{W}$ motif is involved in triggering Rpi-blb1-mediated cell death, we analyzed several deletion mutants of ipiO2 (Fig. 3A). In agro-coinfiltration assays in $N$. benthamiana, IPI-O2-with or without its signal peptide - triggers cell death in the presence of Rpi-blb1. Deleting the domain comprising the RXLR, RGD, and dEER motifs did not abolish recognition, and even an additional deletion of the first 26 amino acids of the C-terminal domain did not change the cell-death response. Agroinfection and rub-inoculation assays on S. stoloniferum accession sto17605-4, which harbors the Rpi-blbl homolog Rpi-stol, resulted in similar responses and showed that recognition of IPI-O by Rpi-stol follows the same pattern. The results show that the region spanning the last 54 amino acids of IPI-O and comprising the W motif is sufficient for recognition by Rpi-blb1 and Rpi-sto1. Since the only mutations that are consistent between, on the one hand, the class I and II variants and, on the other hand, the class III variant are located within the $\mathrm{W}$ motif, it is conceivable that this motif plays a role in recognition of IPI-O by Rpi-blb1.

\section{IPI-O variants of classes I and II but not class III trigger Rpi-blb1-mediated cell death.}

In a previous study, we showed that the class I ipiO variants, ipiO1 and ipiO2, trigger Rpi-blb1-mediated cell death. To assess whether the newly identified ipiO variants are also recognized by Rpi-blbl, we used agroinfiltration in $N$. benthamiana to reconstruct the interaction between the ipiO variants and Rpi-blbl. Coinfiltration of $N$. benthamiana leaves with an Agrobacterium tumefaciens strain carrying a construct expressing Rpi-blbl as well as a strain carrying a construct expressing either class I ipiO genes (ipiO1, ipiO2, ipiO5, ipiO7, and ipiO8) or class II ipiO genes (ipiO3) resulted in a confluent cell-death response (Fig. 3B). Also class I ipiO variant ipiOm2 of $P$. mirabilis coinfiltrated with Rpi-blbl resulted in cell death (data not shown). In contrast, coexpression of Rpi-blbl with the class III ipiO4 gene did not elicit a Rpi-blb1-mediated response, as no visible cell death was observed in the infiltrated leaves.

\section{IpiO variants are expressed in planta.}

To enable expression analyses of $\mathrm{ipiO}$ variants belonging to the three classes, class-specific primers were designed that were tested for specificity on genomic DNA (Fig. 4). Subsequently, RNA isolated from potato leaves infected with $P$. infestans isolates PIC99183, PIC99189, and PIC99177 was analyzed by semiquantitative reverse transcription (RT)-PCR. As shown in Figure 4, mRNA derived from class I, II, and III ipiO

Table 1. Occurrence of ipiO variants and classes in isolates of Phytophthora infestans and related species

\begin{tabular}{|c|c|c|c|c|c|c|c|c|c|c|c|c|c|c|c|}
\hline \multirow[b]{2}{*}{ Phytophthora spp. } & \multirow[b]{2}{*}{ Isolate } & \multicolumn{9}{|c|}{ Class I } & \multicolumn{3}{|c|}{ II } & \multirow{2}{*}{$\frac{\text { III }}{\text { ipiO4 }}$} & \multirow{2}{*}{ ipiOm1 ipiOp1 } \\
\hline & & ipiO1 & ipiO2 & ipiO5 & ipiO6 & ipiO7 & ipiO8 & ipiO9 & ipiO10 & 0 ipiO11 & ipiO12 ipiOm2 & ipiO3 & $\overline{i p i O 13}$ & & \\
\hline \multirow{26}{*}{ P. infestans } & F95573 & $\mathrm{X}$ & $\mathrm{X}$ & & & & & & & & & & & & \\
\hline & 89148-09 & $\mathrm{X}$ & & & & & & & & & & & & & \\
\hline & PIC99177 & & & & & & & & & & & $\mathrm{X}$ & & & \\
\hline & 88069 & $\mathrm{X}$ & $\mathrm{X}$ & & & & & & & & & $\mathrm{X}$ & & & \\
\hline & PIC99189 & & & & & & & & & & & $\mathrm{X}$ & & $\mathrm{X}$ & \\
\hline & 90128 & $\mathrm{X}$ & $\mathrm{X}$ & & & & & & & $\mathrm{X}$ & & & & & \\
\hline & $\mathrm{EC} 1$ & $\mathrm{X}$ & $\mathrm{X}$ & & & & & & & $\mathrm{X}$ & & $\mathrm{X}$ & & & \\
\hline & H3OP04 & $\mathrm{X}$ & & & & & & & & $\mathrm{X}$ & & $\mathrm{X}$ & & & \\
\hline & USA618 & $\mathrm{X}$ & $\mathrm{X}$ & & & & & & & & & & & & \\
\hline & IPO-0 & $\mathrm{X}$ & & & & & & & & & & & & $\mathrm{X}$ & \\
\hline & IPO-C & $\mathrm{X}$ & & & & & & & & & & $\mathrm{X}$ & & & \\
\hline & PIC99183 & & & & & & & & & $\mathrm{X}$ & $\mathrm{X}$ & & & & \\
\hline & NL01096 & $\mathrm{X}$ & $\mathrm{X}$ & & & & & & & & & $\mathrm{X}$ & & & \\
\hline & VK98014 & $\mathrm{X}$ & $\mathrm{X}$ & & & & & & & & & & $\mathrm{X}$ & & \\
\hline & IPO428-2 & $\mathrm{X}$ & $\mathrm{X}$ & & & & & & & $\mathrm{X}$ & & & & & \\
\hline & NL00228 & $\mathrm{X}$ & $\mathrm{X}$ & & & & & & & & & & $\mathrm{X}$ & & \\
\hline & DDR7704 & & $\mathrm{X}$ & & & & & & & & & & & & \\
\hline & UK7824 & & $\mathrm{X}$ & & & & & & & & & & & $\mathrm{X}$ & \\
\hline & 89094 & & & $\mathrm{X}$ & & & $\mathrm{X}$ & $\mathrm{X}$ & & & & $\mathrm{X}$ & & & \\
\hline & 91011 & $\mathrm{X}$ & & & $X$ & $\mathrm{X}$ & & & $\mathrm{X}$ & & & & & & \\
\hline & PIC97757 & $\mathrm{X}$ & & & $\mathrm{X}$ & $\mathrm{X}$ & & & $\mathrm{X}$ & & & & & & \\
\hline & IPO98014 & & & $\mathrm{X}$ & & & $\mathrm{X}$ & $\mathrm{X}$ & & & & $\mathrm{X}$ & & & \\
\hline & NL050105 & & $\mathrm{X}$ & & & & & & & & & $\mathrm{X}$ & & & \\
\hline & NL05194 & & $\mathrm{X}$ & & & & & & & & & $\mathrm{X}$ & & & \\
\hline & PRC505705 & & $\mathrm{X}$ & & & & & & & & & & & & \\
\hline & PRC506303 & & $\mathrm{X}$ & & & & & & & & & & & & \\
\hline \multirow[t]{3}{*}{ P. infestans s.1. ${ }^{\mathrm{a}}$} & EC3260 & & & & & & & & & & & & & $\mathrm{X}$ & \\
\hline & EC3394 & & & & & & & & & & & & & $\mathrm{X}$ & \\
\hline & EC3364 & $\mathrm{X}$ & $\mathrm{X}$ & & & & & & & & & $\mathrm{X}$ & & & \\
\hline$P$. andina & EC3414 & & & & & & & & & & & & & $\mathrm{X}$ & \\
\hline P. ipomoeae & PIC99193 & & & & & & & & & & $\mathrm{X}$ & & & & \\
\hline P. phaseoli & CBS556.88 & & & & & & & & & & & & & & $\mathrm{X}$ \\
\hline \multirow{2}{*}{ P. mirabilis } & PIC99111 & & & & & & & & & & $\mathrm{X}$ & & & & \\
\hline & CBS150.88 & & & & & & & & & & & & & & $\mathrm{X}$ \\
\hline
\end{tabular}

\footnotetext{
a s.l. = sensu lato
} 
genes is present, demonstrating that all three classes comprise functional genes that are expressed during in planta growth.

\section{Isolates lacking class I ipiO variants are virulent on Rpi-blb1 plants.}

To test whether the identified ipiO variants determine $R p i$ blb1-mediated cell death, we performed infection assays using $P$. infestans isolates that are genetically diverse and carry different classes of $i p i O$ variants (Fig. 1, Table 1). To allow a correct interpretation of the virulence phenotypes of the isolates on Rpi-blb1 plants, we first tested 16 selected isolates for their infection capabilities on potato. Detached leaves of universal susceptible potato cultivar Désirée were inoculated and, at 6 days postinoculation (dpi), lesion diameters were measured. Based on lesion size (LS), the isolates were grouped in three classes of aggressiveness (Supplementary Table 3). To investigate the specificity spectrum of Rpi-blb1, we inoculated the 16 isolates on the $S$. bulbocastanum accession blb8005-8, which is the genotype from which Rpi-blbl was isolated, and included Désirée and $S$. bulbocastanum blb2002-containing Rpi-blb2-as susceptible and resistant controls, respectively (Table 3). Lesion diameters were measured at 4, 5, and 6 dpi, and LS, lesion growth rates (LGR), and infection efficiency (IE) were calculated. Large lesions exceeding $25 \mathrm{~mm}^{2}$ always coincided with massive sporulation and were scored as compatible interactions. In contrast, smaller lesions typically did not sporulate or showed a 'black-spot' phenotype, indicating a $\mathrm{HR}$. As expected for the so-called broad-spectrum $R$ gene $R p i$ $b l b 1$, blb8005-8 was incompatible with nearly all isolates. Two Mexican isolates, PIC99177 and PIC99189, however, were clearly compatible with blb8005-8 and both developed sporulating lesions on blb8005-8 leaves.

To investigate the correlation between compatibility or incompatibility and $i p i O$ variants, we compared the virulence phenotypes of the isolates on Rpi-blb1-containing host plants with the occurrence or the absence of specific ipiO variants. All avirulent isolates contained at least one class I ipiO variant (Tables 1 and 3 ). In contrast, no class I ipiO variants were found in the two virulent isolates PIC99189 and PIC99177; only class II and III ipiO variants were detected. These results suggest that class I ipiO variants determine avirulence of $P$. infestans isolates on Rpi-blbl plants.

To verify these findings, we tested the $P$. infestans isolates on transgenic lines of cultivar Impala and cultivar Désirée containing Rpi-blb1 as transgene. In general, Rpi-blb1-meditated resistance levels in the potato transgenic lines were lower than in its wild Solanum background, blb8005-8 (Table 3). In accordance with the previous experiment, isolate PIC99189 was able to establish sporulating lesions on transgenic Impala RGC-2A9 expressing Rpi-blbl, whereas isolates IPO-C and 90128 displayed a HR (Fig. 5). On five Désirée Rpi-blb1 transformants, including A01-20, we quantitatively assessed the resistance levels. The virulent isolates PIC99177 and PIC99189 infected A01-20 (Table 3) and the other four transgenic lines (data not shown) equally well as the Désirée control plants (analysis of variance, $P<0.05$ ). To the other 14 isolates, the Rpi-blbl transgene conferred enhanced resistance at various levels, and generally, the level of resistance negatively correlated with the aggressiveness of the isolates. The moderately aggressive isolates F95573, 89148-09, and 88069 reached only low levels of IE and LGR on A01-20, and Rpi-blb1 clearly conferred a high level of resistance. Highly aggressive isolates, however, achieved slightly reduced or similar IE and LGR on A01-20 as compared with Désirée control plants and were often able to establish high percentages of fast growing lesions on A01-20, despite the fact that these isolates contain a class I ipiO variant. Obviously, the aggressiveness of the isolates overrules the recognition by Rpi-blbl in the transgenic potato background. The observation that the level of resistance conferred by $R$ genes is influenced by the genetic background in

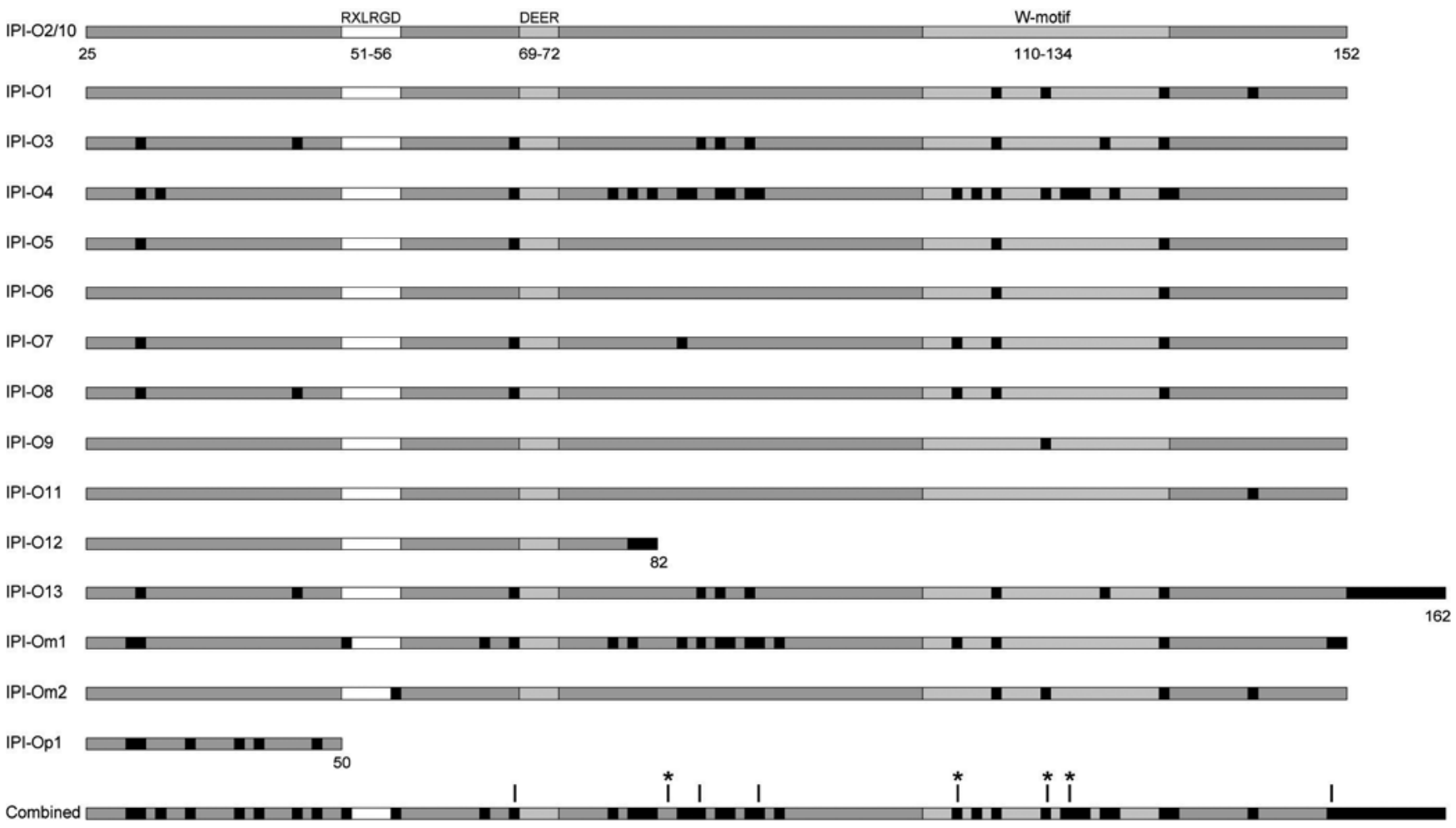

Fig. 1. Thirteen variants of the mature IPI-O protein. The motifs RXLR, RGD, and DEER and a predicted W motif are indicated. Numbers refer to the amino-acid positions. Amino-acid polymorphisms in IPI-O variants, as compared with IPI-O2, are depicted in black. In the lower bar (combined), all the amino acids that show polymorphism are indicated. The vertical lines refer to positively selected sites. $*=P<99 \%$. 
which they reside is in line with previous studies. For example, it was shown that expression of Rpi-blb1 in S. bulbocastanum is dramatically higher than in potato lines carrying Rpi-blbl as a transgene (Bradeen et al. 2009; Kramer et al. 2009).

\section{Recognition specificity of $i p i O$ variants}

\section{by Rpi-blb1 is conserved in Rpi-sto1 and Rpi-pta1.}

Recently, we described the identification and cloning of functional homologs of Rpi-blbl in the distantly related Solanum species S. stoloniferum (Vleeshouwers et al. 2008). The homologs Rpi-stol and Rpi-ptal are nearly identical to Rpi-blb1; they only differ in three and five nonsynonymous nucleotide substitutions, respectively. To test these $R$ genes for ipiO specificity, we coinfiltrated $N$. benthamiana leaves with $A$. tumefaciens strains carrying constructs expressing either Rpi-stol or Rpi-ptal combined with A. tumefaciens strains expressing ipiO variants of class I, II, or III. Leaves coinfiltrated with the Rpiblbl homologs and class I or class II $i p i O$ variants showed a

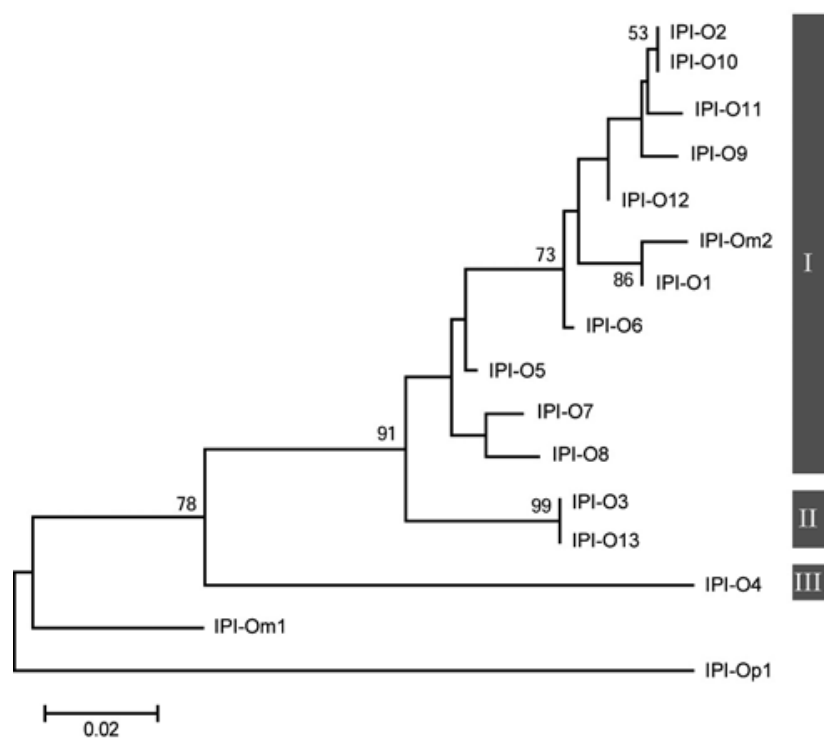

Fig. 2. Phylogenetic relationship and clustering of the IPI-O variants. The minimum evolution tree was rooted with IPI-Op1. Rooting with IPI-Om1, IPI-O4, or Phytophthora sojae Avr1b resulted in similar clustering. Bootstrap values of 1,000 replicates are indicated at the nodes; values less than $50 \%$ are omitted (Felsenstein 1985). The tree is drawn to scale, with branch lengths in the same units as those of the evolutionary distances used to infer the phylogenetic tree. Class I, II, and III IPI-O variants are indicated. confluent cell-death response, but leaf panels coinfiltrated with class III ipiO did not show cell death (Supplementary Fig. 4). These results demonstrate that, similar to Rpi-blb1, Rpi-stol or Rpi-ptal display differential specificity towards the different classes of $\mathrm{ipiO}$ variants.

We also investigated how $S$. stoloniferum sto17605-4 and pta17831-8 responded to infection with the 16 P. infestans isolates that posses different variants of ipiO. In detached leaf assays, infection of sto17605-4 and pta17831-8 with the isolates PIC99189 and PIC99177 resulted in sporulating lesions, in accordance with the results obtained with blb8005-8. Of the other 14 isolates, only PIC99183 formed a few lesions on sto17605-4 and pta17831-8. There was, however, no biotrophic growth nor sporulation and the lesions expanded very slowly. Since the LGR and IE parameters were much lower than expected for such a highly aggressive isolate, we suspect that the necrotic spots are due to a trailing HR following invasion attempts but not to specific virulence of PIC99183 on S. stoloniferum sto17605-4 and pta17831-8.

\section{DISCUSSION}

Rpi-blbl is classified as a so-called broad-spectrum $R$ gene that confers resistance to a broad range of $P$. infestans isolates (Song et al. 2003; van der Vossen et al. 2003). In a recent study, we identified the RXLR-dEER effector IPI-O as the candidate for the cognate Avr factor of Rpi-blb1 (Vleeshouwers et al. 2008). In this study, we detected isolates that are virulent on Rpi-blb1 plants and showed that Rpi-blb1-ipiO is an $R$-Avr pair that basically interacts according to the gene-for-gene model (Flor 1971). IPI-O is the effector that triggers ETI in plants carrying Rpi-blbl, whereas changes in the IPI-O effector repertoire result in loss of ETI.

The $i p i O$ gene family is highly diverse but restricted to Phytophthora species that belong to clade 1c. Profiling 34 isolates of $P$. infestans and its close relatives revealed $16 \mathrm{ipiO}$ variants, 14 of which were grouped in three distinct classes. In $P$. infestans sensu latu, $P$. andina, $P$. ipomoeae, $P$. phaseoli, and $P$. mirabilis, which all evolved on host species distant from Solanum section Petota, a more or less equal distribution of class I, II, and III variants was found, and in addition, two more distant ipiO variants were detected. In $P$. infestans however, class I was significantly expanded, with one to four class I variants in most isolates, of which the majority also has one class II or one class III variant or both. Class I includes ipiOI and ipiO2, the variants that were already isolated in the early $1990 \mathrm{~s}$ (Pieterse et al. 1994) and, more recently, were identified as Avr-

Table 2. Evidence for positively selected sites in ipiO

\begin{tabular}{|c|c|c|c|}
\hline Model code & Parameter estimates & $\ell^{\mathbf{a}}$ & Positively diversified codons ${ }^{b}$ \\
\hline \multicolumn{4}{|l|}{$\mathrm{Pi}^{\mathrm{c}}$} \\
\hline M0: one ratio & $\omega=1.089$ & -839.78 & Not allowed \\
\hline M1a: nearly neutral & $\omega 0=0, \omega 1=1, p 0=0.580, p 1=0.420$ & -835.50 & Not allowed \\
\hline M2a: positive selection & $\omega 0=0, \omega 1=1, \omega 2=28.638, p 0=0.353, p 1=0.637, p 2=0.010$ & -822.55 & $46 \mathrm{~N}, 82 \mathrm{Y}, 85 \mathrm{M}, 87 \mathrm{~L}, 113 \mathrm{~A}^{*}, 122 \mathrm{R} *, 124 \mathrm{~L} *$ \\
\hline M7: beta & $p=0.012, q=0.005$ & -837.03 & Not allowed \\
\hline M8: beta and $\omega$ & $p 0=0.990, p 1=0.010, p=0.008, q=0.005, \omega=27.108$ & -822.57 & $46 \mathrm{~N}, 82 \mathrm{Y}, 85 \mathrm{M}, 87 \mathrm{~L}, 113 \mathrm{~A}^{*}, 122 \mathrm{R} *, 124 \mathrm{~L} *$ \\
\hline \multicolumn{4}{|l|}{$\mathrm{Pi}+\mathrm{Pm}^{\mathrm{d}}$} \\
\hline M0: one ratio & $\omega=0.970$ & -980.05 & Not allowed \\
\hline M1a: nearly neutral & $\omega 0=0, \omega 1=1, p 0=0.599, p 1=0.401$ & -972.94 & Not allowed \\
\hline M2a: positive selection & $\omega 0=0.476, \omega 1=1, \omega 2=12.487, p 0=0.971, p 1=0, p 2=0.028$ & -960.76 & $85 \mathrm{M}^{*}, 93 \mathrm{G}, 113 \mathrm{~A}^{*}, 122 \mathrm{R} *, 124 \mathrm{~L}$ \\
\hline M7: beta & $p=0.005, q=0.007$ & -972.94 & Not allowed \\
\hline M8: beta and $\omega$ & $p 0=0.983, p 1=0.017, p=0.005, q=0.005, \omega=14.665$ & -960.34 & $\begin{array}{l}68 \mathrm{~S}, 85 \mathrm{M}^{*}, 87 \mathrm{~L}, 93 \mathrm{G}, 113 \mathrm{~A}^{*}, 122 \mathrm{R}^{*}, 124 \mathrm{~L}^{*} \text {, } \\
151 \mathrm{P}\end{array}$ \\
\hline
\end{tabular}

\footnotetext{
${ }^{a}$ Log likelihood value.

${ }^{\mathrm{b}}$ Bayes Empirical Bayes analysis (Yang et al. 2005). Positively selected sites $(P>95 \%, *=P>99 \%)$.

${ }^{\mathrm{c}}$ Based on full-length $P$. infestans ipiO variants, $n=11$.

${ }^{\mathrm{d}}$ Based on full-length $P$. infestans and $P$. mirabilis ipiO variants, $n=13$.
} 
blb1 (Vleeshouwers et al. 2008). Disease testing on Solanum species showed that all isolates with class I ipiO variants were avirulent on Rpi-blbl plants, which is in line with the previously reported broad-spectrum character of this $R$ gene (Song et al. 2003; van der Vossen et al. 2003). In contrast, two Mexican $P$. infestans isolates, PIC99189 and PIC99177, each of which lack class I ipiO variants, appeared to be virulent on Rpi-blbl plants. These data suggest that absence of class I ipiO genes is correlated with virulence on Rpi-blbl plants, and this is supported by the observation that coinfiltration of class I ipiO variants and Rpi-blbl in N. benthamiana leaves results in cell death. Apparently, class I IPI-O variants elicit HR in Rpi-blbl plants and this arrests pathogen invasion. Class III ipiO appeared unable to induce cell death when coinfiltrated with Rpi-blbl, thus strongly suggesting that the presence of class III ipiO in $P$. infestans strains is indeed unlikely to confer avirulence. It should be noted, though, that we have not used epitope-tagged constructs in our in planta expression assays to monitor the stability of the various IPI-O variants and, hence, cannot exclude the pos- sibility that class III IPI-O is less stable than class I or II IPIO. A more puzzling issue is the finding that class II variants elicit cell death when coinfiltrated with Rpi-blbl in N. benthamiana leaves. The class II variant ipiO3 was found to be expressed in planta in the virulent strain, and one would expect that the presence of a class II variant together with the Rpiblb1 resistance protein in one cell would lead to HR. This is not the case and raises the question how the numerous RXLR effectors that are predicted to be targeted to the host cell interact with each other. In reconstruction experiments, for example, some RXLR effectors suppress cell death induced by other effectors such as elicitins or BAX (Bos et al. 2009; Bouwmeester et al. 2008; Dou et al. 2008). In vivo, there could well be a kind of synergism between class I and class II IPI-O variants or even other RXLR effectors. For example, when class I is lacking, the class II variant might not be potent enough to act as Avr factor by itself. Alternatively, the presence of a class I variant could suppress the virulence function of a class II variant by competition for the same virulence target. One

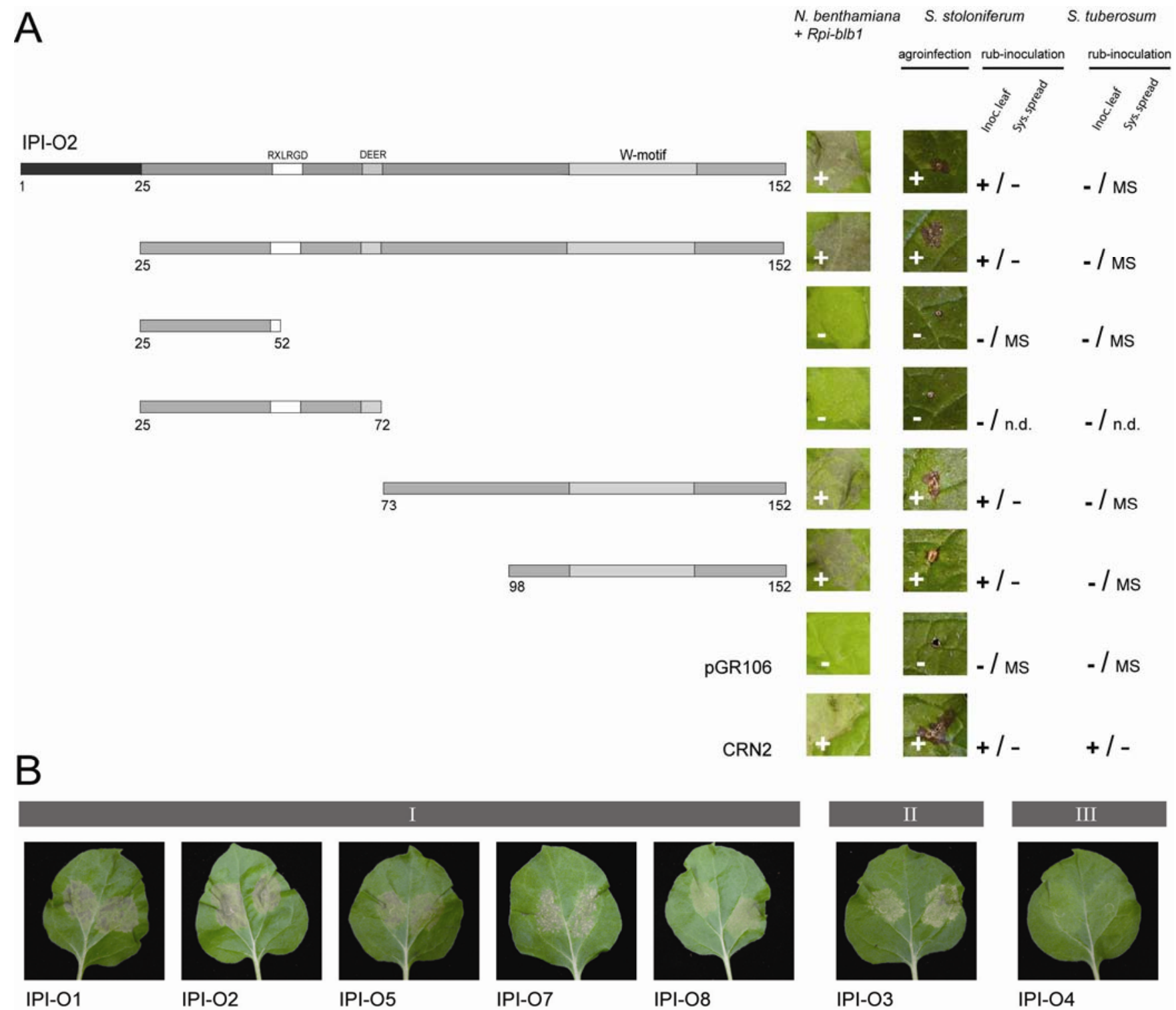

Fig. 3. A, The $\mathrm{C}$ terminus of IPI-O comprising the $\mathrm{W}$ motif is sufficient for recognition by Rpi-blb1. Deletion mutants of ipiO2 were agro-coinfiltrated with Rpi-blbl in Nicotiana benthamiana or were agroinfected or rub-inoculated with Potato virus $X$ particles carrying the deletion mutants on Solanum stoloniferum accession 17605-4. Potato cultivar Bintje was used as control. Mosaic symptoms (MS) indicate virus spread. Pictures were taken at 5 days after infiltration or agroinfection. B, Class I and II IPI-O variants are recognized by Rpi-blb1. N. benthamiana leaves were agroinfiltrated at both sides of the leaf midrib with $R p i-b l b 1$ in combination with $i p i O$ variants of classes I, II, or III. Pictures were taken at 5 days after infiltration. 
can also not rule out the possibility that the class II variants are less stable in planta than the class I variants. The finding of a class III variant that is not recognized by Rpi-blbl but is expressed in planta makes the situation even more complex.

Nevertheless, the clear distinction between the three classes helped us to define which parts of the protein are involved in recognition by Rpi-blb1. Deletion analysis showed that the $\mathrm{C}$ terminal part of the IPI-O effector protein is required for recognition, which is in line with other studies (Bos et al. 2006; Dou et al. 2008). The smallest fragment that we tested is 54 amino acids in length and comprises the single $\mathrm{W}$ motif that is present in IPI-O. For Phytophthora sojae Avr1b, specific amino-acid residues in the $\mathrm{W}$ - and Y-motifs in Avr1b are responsible for recognition by the RPS1 protein as well as suppressor activity of cell death. In IPI-O, the $\mathrm{W}$ motif is the region that is the most divergent in the class III variants, and the three amino acids that show positive selection are all located within the W motif. More detailed analysis of the role of each individual amino-acid residue in the $\mathrm{W}$ motif will reveal the exact determinants of recognition by Rpi-blb1.

In recent years, insights into $R$ gene-based resistance in potato and the role of cognate Avr genes from $P$. infestans have

\begin{tabular}{|c|c|c|c|c|c|c|c|c|c|}
\hline \multirow[b]{2}{*}{ Class } & \multicolumn{4}{|c|}{ gDNA } & \multicolumn{5}{|c|}{ RT-PCR } \\
\hline & & & ॥ & III & & & II & III & \\
\hline pio & 12 & 11 & 3 & 4 & 12 & 11 & 3 & 4 & ef2 \\
\hline PIC99183 & $=$ & $=$ & & & & & & & \\
\hline PIC99189 & & & - & $=$ & & & 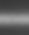 & & \\
\hline PIC99177 & & & $=$ & & & & & & \\
\hline
\end{tabular}

Fig. 4. Expression of ipiO in infected potato leaves. IpiO class-specific primers were used for semiquantitative reverse transcription-polymerase chain reactino on RNA isolated from infected leaf tissue of potato cultivar Bintje at 6 days postinoculation. To demonstrate that the primers are specific for each of the three ipiO classes, genomic DNA of Phytophthora infestans isolates PIC99183, PIC99189, and PIC99177 was used as template and detection of specific ipiO variants was confirmed. The $P$. infestans elongation factor 2 gene (ef2) was used as a control to determine the integrity of the RNA. increased. For example, many studies were performed for the $R 3 a$-Avr $3 a$ model system. The $R 3 a$-harboring species $S$. demissum coexists with $P$. infestans in the cool and humid mountain forests in Toluca Valley, a perfect condition for a tight coevolution between $R 3 a$ and $A v r 3 a$. R3a is a typical fast-evolving type I $R$ gene (Huang 2005; Kuang et al. 2005), resulting in numerous $R 3 a$-like genes (Friedman and Baker 2007; Huang 2005). For Avr3a, only two alleles have been detected; $A v r 3 a^{E M}$ is present in most $P$. infestans isolates world-wide (Armstrong et al. 2005; Rivera-Peña 1990b), whereas $A v r 3 a^{K I}$ is much less abundant. Avr3a ${ }^{\mathrm{KI}}$ but not Avr3a ${ }^{\mathrm{EM}}$ is recognized by R3a, thus resulting in defeat of $R 3 a$ by most $P$. infestans isolates. $R 1, R 2$, and $R 4$ also originate from $S$. demissum and, similar to $R 3 a$, these $R$ genes were quickly defeated in the field (Fry 2008). Similar to Avr $3 a$, Avr4 alleles in field isolates show very little variation and, in all virulent strains, the Avr4 gene is out of frame, due to a 1 base pair deletion (van Poppel et al. 2008). Preliminary analysis of $A v r 1$ and $A v r 2$ indicates also that these Avr genes are represented by only a few alleles (F. Govers, P. Birch, and E. Gilroy, personal communication). A completely different scenario exists for the Rpi-blb-ipiO interaction. Rpi-blbl originates from $S$. bulbocastanum, which occurs in more arid climates and most likely has less intensive encounters with $P$. infestans. Presence of Rpi-blb1 homologs in other Mexican species such as $S$. stoloniferum (Wang et al. 2008) that partly grow in P. infestans conducive climates creates the opportunity for virulent strains to evolve on these species. Indeed, the virulent strains PIC99189 and PIC99177 described in this study were collected from $S$. stoloniferum host plants in Mexico (Flier et al. 2002). Both Rpistol and Rpi-ptal are almost identical to Rpi-blbl, and Rpi-blbl fulfills the criteria of a type II $R$ gene with only little diversifying selection that is typically slow evolving (Kuang et al. 2005; Liu and Halterman 2006). Thus, for the Rpi-blb1-ipiO interaction, not the $R$ gene but the $A v r$ gene is represented by a highly diverse and extensive gene family. The notable expansion of class I ipiO in P. infestans but not in related Phytophthora species that infect other plant species might be due to a certain degree of coevolution between Avr-blb1 and Rpi-blbl homologs in Solanum host plants. Also Rpi-blb2, another broad-spectrum $S$. bulbocastanum $R$ gene that is not (yet) defeated, is interacting with a highly diverse $A v r$ gene family, and perhaps such $A v r$ genes may be less easy to overcome (S. Kamoun, personal communication).

Table 3. Phytophthora infestans isolates virulent on Solanum plants containing Rpi-blbl lack class I ipiO variants

\begin{tabular}{|c|c|c|c|c|c|c|c|c|c|c|c|c|c|c|c|c|}
\hline \multirow[b]{3}{*}{ P. infestans isolate ${ }^{a}$} & \multicolumn{12}{|c|}{ Plant material } & \multirow[b]{3}{*}{$* \mathbf{c}$} & \multirow{2}{*}{\multicolumn{3}{|c|}{ ipiO class }} \\
\hline & \multicolumn{2}{|c|}{ blb8005-8 } & \multicolumn{2}{|c|}{ sto17605-4 } & \multicolumn{2}{|c|}{ pta17831-8 } & \multicolumn{2}{|c|}{ A01-20 } & \multicolumn{2}{|c|}{ Désirée } & \multicolumn{2}{|c|}{ blb2002 } & & & & \\
\hline & $\mathbf{I E}^{\mathbf{b}}$ & $\mathbf{L G R}^{\mathbf{b}}$ & IE & LGR & IE & LGR & IE & LGR & IE & LGR & IE & LGR & & $\mathbf{I}$ & II & III \\
\hline F95573 & 0 & 0 & 0 & 0 & 0 & 0 & 3 & 1.4 & 69 & 4.4 & 0 & 0 & A & $X$ & & \\
\hline 89148-09 & 0 & 0 & 0 & 0 & 0 & 0 & 16 & 1.1 & 69 & 2.7 & 0 & 0 & A & $X$ & & \\
\hline 88069 & 0 & 0 & 0 & 0 & 0 & 0 & 22 & 0.6 & 100 & 3.2 & 0 & 0 & A & $X$ & $X$ & \\
\hline 90128 & 0 & 0 & 0 & 0 & 0 & 0 & 50 & 3.7 & 78 & 3.4 & 0 & 0 & A & $X$ & & \\
\hline EC1 & 0 & 0 & 0 & 0 & 0 & 0 & 31 & 2.5 & 84 & 3.7 & 0 & 0 & A & $\mathrm{X}$ & $\mathrm{X}$ & \\
\hline IPO-0 & 0 & 0 & 0 & 0 & 0 & 0 & 78 & 3.4 & 91 & 3.8 & 0 & 0 & A & $\mathrm{X}$ & & $\mathrm{X}$ \\
\hline PIC99183 & 0 & 0 & 50 & 0.5 & 63 & 1.2 & 88 & 3.6 & 91 & 3.6 & 0 & 0 & A & $X$ & & \\
\hline Н30Р04 & 0 & 0 & 0 & 0 & 0 & 0 & 9 & 2.4 & 100 & 4.4 & 0 & 0 & A & $X$ & $X$ & \\
\hline IPO-C & 0 & 0 & 0 & 0 & 0 & 0 & 50 & 2.9 & 100 & 3.9 & 0 & 0 & A & $X$ & $X$ & \\
\hline USA618 & 0 & 0 & 0 & 0 & 0 & 0 & 19 & 3.5 & 100 & 3.4 & 0 & 0 & A & $X$ & & \\
\hline NL01096 & 0 & 0 & 0 & 0 & 0 & 0 & 66 & 3.4 & 100 & 3.8 & 0 & 0 & A & $X$ & $X$ & \\
\hline VK98014 & 0 & 0 & 0 & 0 & 0 & 0 & 66 & 1.8 & 100 & 4.7 & 0 & 0 & A & $X$ & $X$ & \\
\hline IPO428-2 & 0 & 0 & 0 & 0 & 0 & 0 & 38 & 1.9 & 100 & 4.2 & 0 & 0 & A & $X$ & & \\
\hline NL00228 & 0 & 0 & 0 & 0 & 0 & 0 & 47 & 4.6 & 100 & 4.8 & 0 & 0 & A & $X$ & $X$ & \\
\hline PIC99177 & 72 & 1.1 & 75 & 2.6 & 81 & 2.9 & 50 & 2.8 & 88 & 3.0 & 0 & 0 & $\mathrm{~V}$ & & $\mathrm{X}$ & \\
\hline PIC99189 & 34 & 1.1 & 75 & 0.9 & 100 & 4.3 & 91 & 4.5 & 91 & 3.6 & 0 & 0 & $\mathrm{~V}$ & & $\mathrm{X}$ & $\mathrm{X}$ \\
\hline
\end{tabular}

a Additional information about the aggressiveness of the $P$. infestans isolates on potato cultivar Désirée can be found in Supplementary Table 3.

${ }^{\mathrm{b}}$ Isolates were inoculated on different Solanum plants containing Rpi-blbl or its homologs and mean infection efficiency (IE) and lesion growth rate (LGR) were determined.

c *Phenotype on Rpi-blb1 plants. $\mathrm{A}=$ avirulent; $\mathrm{V}=$ virulent. 

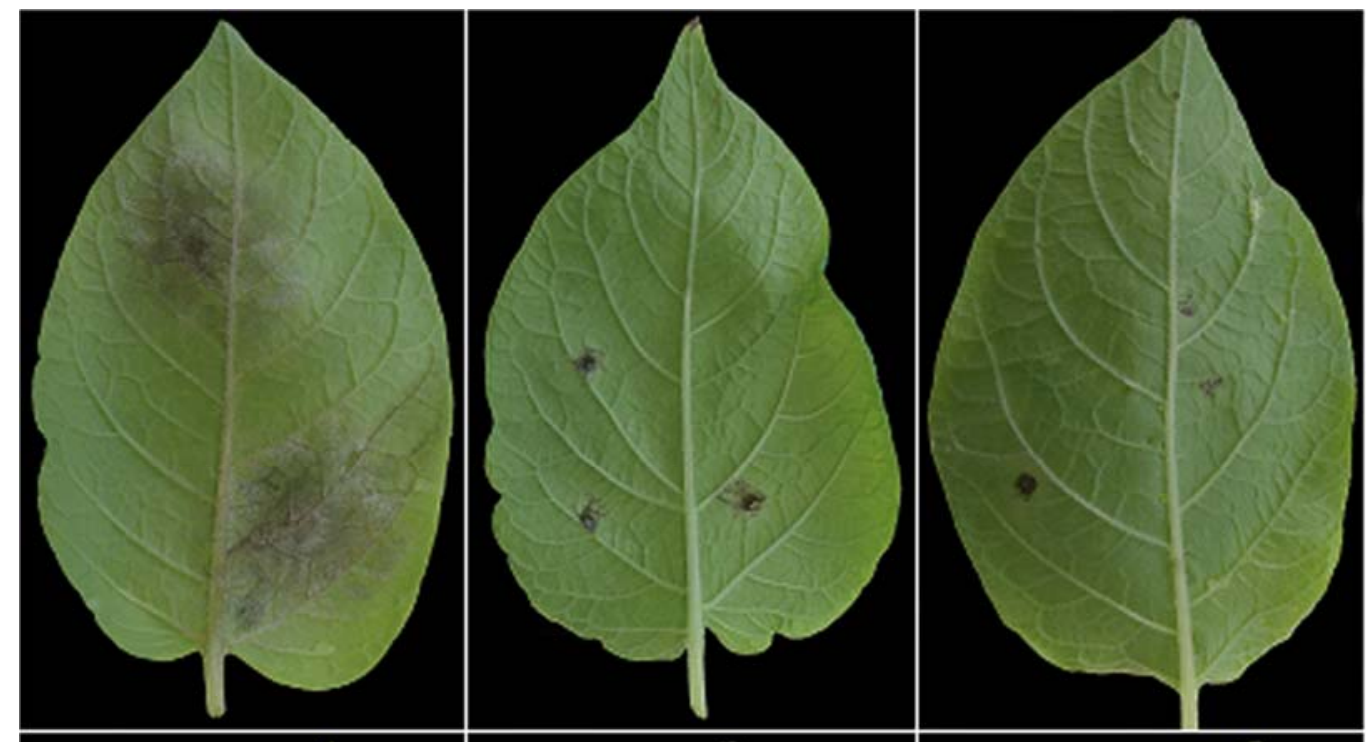

IPO-C
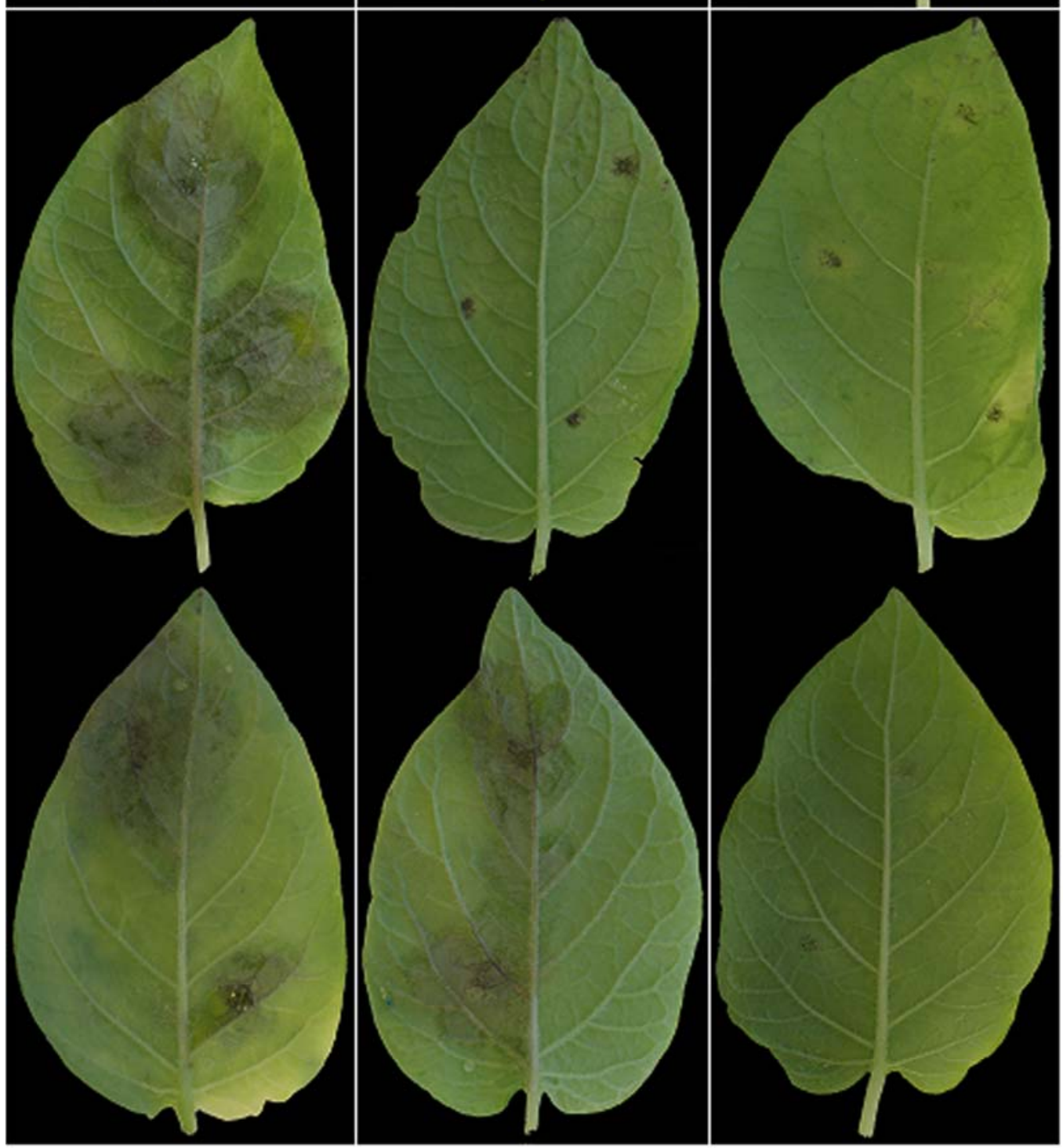

90128

\section{PIC99189}

\section{Impala}

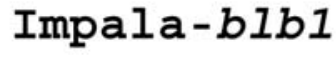

Impala-blb2

Fig. 5. Rpi-blb1 transgenic potato lines are resistant to Phytophthora infestans isolates carrying ipiO class I variants, class II variants, or both. Pictures were taken at 6 days postinoculation. 
In the wild Solanum species that contain Rpi-blbl or a functional homolog, full resistance was conferred to all tested avirulent $P$. infestans isolates, with the exception of the two Mexican strains. The transfer of Rpi-blbl into potato cultivars resulted in improved protection to $P$. infestans isolates. The enhanced resistance, however, could only arrest the growth of mild isolates. Aggressive isolates were not blocked and could still cause high percentages of lesions expanding at high rates. The influence of the genetic background on the performance of Rpi-blbl was also reported in other studies, in which the basal Rpi-blbl expression levels were found dramatically higher in its wild $S$. bulbocastanum origin compared with transgenic potato (Bradeen et al. 2009; Kramer et al. 2009). Also the increase in expression after $P$. infestans inoculation was higher. These studies suggest that expression of Rpi-blb1 as transgene in potato is not high enough to provide satisfactory resistance in the field, and this implies that stacking with other $R$ genes or engineering enhanced transgene expression in cultivars is recommended.

The future of late blight resistance breeding is controlled application of well-studied $R$ genes in high quality potato cultivars and devising inherent durability predictions based on the interacting Avr gene. Potato cultivars engineered with Rpi-blbl and Rpi-blb2 are expected to be the first genetically modified potatoes to be cultivated for consumption purposes in Europe (Application GM field trial 2005). Rpi-blbl is still effective to a broad range of isolates; virulent isolates similar to PIC99189 and PIC99177 have not (yet) been detected in The Netherlands and neighboring countries, and class I ipiO is well-represented in the $P$. infestans isolates analyzed thus far. Future large-scale monitoring aimed at diagnosing the ipiO classes in the $P$. infestans population can help determine whether virulence to Rpi-blbl is evolving in commercial potato growing areas or whether accidental introduction of potentially virulent $P$. in festans has occurred. When the first virulent isolates are detected, selection pressure towards losing class I ipiO might be avoided by omitting cultivars with Rpi-blbl for a certain period of time and applying other $R$ genes instead.

\section{MATERIALS AND METHODS}

\section{Phytophthora isolates, culture conditions, and inoculum preparation.}

The Phytophthora isolates used in this study were retrieved from our in-house collection or were provided by colleagues. Phytophthora isolates were routinely grown in the dark at $15^{\circ} \mathrm{C}$ in liquid Plich medium (van der Lee et al. 1997) prior to DNA extraction (Lees et al. 2006) or on solid rye sucrose medium (Caten and Jinks 1968) prior to disease tests. To isolate zoospores for plant inoculations, sporulating mycelium was flooded with cold water and incubated at $4^{\circ} \mathrm{C}$ for 1 to $3 \mathrm{~h}$.

\section{Cloning of $i p i O$ variants.}

Primers (Supplementary Table 2) and Pfu DNA polymerase (Promega, Charbonnnières, France) were used to amplify ipiO on genomic DNA. After 30 cycles, SuperTaq polymerase (HT Biotechnology, Cambridge) and its buffer were added, followed by $15 \mathrm{~min}$ at $72^{\circ} \mathrm{C}$. The obtained amplicons were cloned into pGEM-T Easy vector (Promega) and were transformed in DH5 $\alpha$ competent cells (Invitrogen, Carlsbad, CA, U.S.A.). Sequencing was performed using universal M13 primers and DNA sequences were analyzed using DNAstar v6, Chromas 2.3 (Technelysium, Tewantin, Australia) and Vector NTI software.

\section{SSR genotyping.}

SSR genotyping was performed using two multiplex sets of four SSR markers each (SSR1, SSR3, SSR7, SSR11, and SSR2,
SSR4, SSR6, SSR8). Experimental details can be found at the Eucablight website.

\section{Phylogenetic data analyses.}

The SSR data were analyzed by the phylogenetic software package TREECON for Windows version 1.3b (van de Peer and de Wachter 1994). The evolutionary distance estimation was performed according to Nei and Li (1979), and clustering was performed using the neighbor-joining algorithm. The tree was rooted using isolate IPO-0. Bootstrap values in percentages $(>60)$ from 1,000 replicate trees are shown at the nodes. The scale bar shows genotype divergence as a percentage. Phylogenetic analyses of ipiO sequences were conducted using the minimum evolution method (Rzhetsky and Nei 1992) in MEGA version 4 (Tamura et al. 2007).

\section{Positive selection analysis.}

To test for amino acids under purifying or diversifying selection, we used codon-based analysis (Codeml) implemented in PAML v. 4 package (Yang 2007). Maximum-likelihood codon substitution models M0, M1a, M2a, M7, and M8 were used for analysis. Models M2a and M8 are capable of detecting sites under positive selection. Bayes Empirical Bayes statistics was used to calculate positively selected sites with high posterior probability (Yang et al. 2005).

\section{IpiO expression analysis.}

The zones surrounding the water-soaked lesions, in which ipiOl is known to be highly expressed (van West et al. 1998), were cut from infected leaves of cultivar Bintje at 6 dpi. RNA was isolated using the RNeasy mini kit (Qiagen, Hilden, Germany), was incubated with Dnase, and was purified with the RNA clean-up protocol. The purity of the RNA was confirmed on gel. Semiquantitative RT-PCR was performed with the OneStep RT-PCR kit (Qiagen), using the specific primers RTipiO-I-F and RT-ipiO-I12-R for ipiO12 (class I), RT-ipiO-I-F and RT-ipiO-I11-R for ipiO11 (class I), RT-ipiO-II-F and RTipiO-II-R for ipiO3 (class II), and RT-ipiO-III-F and RT-ipiOIII-R for ipiO4 (class III). P. infestans elongation factor 2 gene (ef2) was used as a control (Torto et al. 2002).

\section{Plant material and generation of Rpi-blb1 transgenic potato plants.}

Solanum plant material used in this study is listed in Supplementary Table 4. Potato cultivars and wild Solanum accessions were obtained from our-in-house collection and the Center of Genetic Resources (CGN), Wageningen, The Netherlands. Solanum plants were maintained in vitro on Murashige and Skoog (MS) medium (Duchefa, Haarlem, The Netherlands) supplemented with $20 \%$ sucrose (MS20) in climate chambers at $18^{\circ} \mathrm{C}$ with a 16-h photoperiod. Top shoots were transferred to fresh medium and, 1 to 2 weeks later, rooted plantlets were transferred to the soil and were grown under greenhouse conditions. $N$. benthamiana plants used for agroinfiltration were grown in climate chambers at 22 to $25^{\circ} \mathrm{C}$ and high light intensity. The generation of the Rpi-blbl transformant in cultivar Impala has been described previously (van der Vossen et al. 2003), and the transformant A01-20 of cultivar Désirée was generated using similar procedures. Briefly, the binary vector pBINPLUS containing Rpi-blbl under control of its native promoter and terminator (van der Vossen et al. 2003) was transformed to A. tumefaciens COR308 and was introduced into cultivar Désirée according to standard protocols (Visser et al. 1991). Regenerative shoots were transferred on solid selective medium Zcvk (MS20 with zeatine at $1 \mathrm{mg}$ liter ${ }^{-1}$, claforan at $200 \mathrm{mg} \mathrm{liter}^{-1}$, vancomycine at $200 \mathrm{mg} l i t e r^{-1}$, and kanamycin at $100 \mathrm{mg} \mathrm{liter}^{-1}$ ) and transformants to solid MS30 with kanamycin at $100 \mathrm{mg} \mathrm{liter}^{-1}$. 


\section{Disease tests.}

Leaves from 6- to 8-week-old plants were detached and placed in water-saturated oases in trays (Vleeshouwers et al. 1999). Leaves were spot-inoculated at the abaxial leaf side with $10-\mu \mathrm{l}$ droplets containing $5 \times 10^{4}$ zoospores per milliliter and were incubated in a climate chamber at $15^{\circ} \mathrm{C}$ with a $16-\mathrm{h}$ photoperiod. Lesion diameters were measured at 4, 5, and 6 dpi. The area of the lesions (LS) and the IE representing the percentage of successful infections were calculated, and the LGR was estimated, using linear regression in GenStat 10.

\section{In planta expression assays.}

IpiO variants without signal peptide were introduced in pK7WG2 and pGR106 (Karimi et al. 2002). R3a, Rpi-blb1, Rpi-stol, and Rpi-ptal with their native expression elements were introduced into the pBINPLUS binary vector (van Engelen et al. 1995). A. tumefaciens GV3101 and AGL1 (Lazo et al. 1991) in combination with the ternary plasmid pBBR1MCS5.virGN54D (van der Fits et al. 2000) were used for transformation. For agroinfiltration, A. tumefaciens strains were grown as described previously (van der Hoorn et al. 2000) to a final optical density at $600 \mathrm{~nm}$ of 0.4 . Leaves of 4- to 5-week-old $N$. benthamiana plants were infiltrated with the A. tumefaciens suspensions (at a 1:1 ratio for coinfiltration) in MMA induction buffer ( 1 liter of MMA $=5 \mathrm{~g}$ of MS salts, $1.95 \mathrm{~g}$ of morpholineethanesulfonic acid, $20 \mathrm{~g}$ of sucrose, $200 \mu \mathrm{M}$ acetosyringone, $\mathrm{pH}$ 5.6), and responses were scored from 3 to 8 days postinfiltration. To obtain Potato virux $X$ (PVX) particles for PVX agroinfection, Agrobacterium strains containing the various recombinant pGR106-ipiO plasmids were agroinfected on $N$. clevelandii plants. After appearance of mosaic symptoms, leaves were ground in $50 \mathrm{mM}$ potassium phosphate buffer $(\mathrm{pH}$ 7.0). Potato plants were rub-inoculated with the obtained homogenate after light dusting with Carborundum powder.

\section{ACKNOWLEDGMENTS}

We thank D. Budding for excellent assistance in disease testing, G. Kessel, P. Birch, B. Fry, and Z. Zhao for providing Phytophthora isolates, T. van de Bosch, M. Visser, H. Smid, R. Jiang, and Z. Zhao for technical assistance, and H. Simon and U. Kopane for bright support. We acknowledge financial support from AVEBE, the Dutch Ministry of Agriculture, Nature and Food Quality (LNV427 Paraplu-plan Phytophthora) and a European Union BioExploit (FOOD-CT-2005-513959).

\section{LITERATURE CITED}

Allen, R. L., Bittner Eddy, P. D., Grenville Briggs, L. J., Meitz, J. C., Rehmany, A. P., Rose, L. E., and Beynon, J. L. 2004. Host-parasite coevolutionary conflict between Arabidopsis and downy mildew. Science 306:1957-1960.

Allen, R. L., Meitz, J. C., Baumber, R. E., Hall, S. A., Lee, S. C., Rose, L. E., and Beynon, J. L. 2008. Natural variation reveals key amino acids in a downy mildew effector that alters recognition specificity by an Arabidopsis resistance gene. Mol. Plant Pathol. 9:511-23.

Application GM field trial 2005. Potato with improved resistance to Phytophthora infestans. BASF Plant Science GmbH.

Armstrong, M. R., Whisson, S. C., Pritchard, L., Bos, J. I., Venter, E., Avrova, A. O., Rehmany, A. P., Bohme, U., Brooks, K., Cherevach, I., Hamlin, N., White, B., Fraser, A., Lord, A., Quail, M. A., Churcher, C., Hall, N., Berriman, M., Huang, S., Kamoun, S., Beynon, J. L., and Birch, P. R. 2005. An ancestral oomycete locus contains late blight avirulence gene $A v r 3 a$, encoding a protein that is recognized in the host cytoplasm. Proc. Natl. Acad. Sci. U.S.A. 102:7766-71.

Blair, J. E., Coffey, M. D., Park, S. Y., Geiser, D. M., and Kang, S. 2008. A multi-locus phylogeny for Phytophthora utilizing markers derived from complete genome sequences. Fungal Genet. Biol. 45:266-77.

Bos, J. I. B., Kanneganti, T. D., Young, C., Cakir, C., Huitema, E., Win, J., Armstrong, M. R., Birch, P. R. J., and Kamoun, S. 2006. The C-terminal half of Phytophthora infestans RXLR effector AVR3a is sufficient to trigger R3a-mediated hypersensitivity and suppress INF1-induced cell death in Nicotiana benthamiana. Plant J. 48:165-76.
Bos, J. I. B., Chaparro-Garcia, A., Quesada-Ocampo, L. M., McSpadden Gardener, B. B., and Kamoun, S. 2009. Distinct amino acids of the Phytophthora infestans effector AVR3a condition activation of R3a hypersensitivity and suppression of cell death. Mol. Plant-Microbe Interact. 22:269-281.

Bouwmeester, K., van Poppel, P. M. J. A., and Govers, F. 2008. Genome biology cracks enigmas of oomycete plant pathogens. Pages 102-134. In: Molecular aspects of plant disease resistance. J. E. Parker, ed. Blackwell publishing, Oxford.

Bradeen, J. M., Iorizzo, M., Mollov, D. S., Raasch, J., Kramer, L. C., Millet, B. P., Austin-Phillips, S., Jiang, J., and Carputo, D. 2009. Higher copy numbers of the potato $R B$ transgene correspond to enhanced transcript and late blight resistance levels. Mol. Plant-Microbe Interact. 22:437-446.

Bryan, G. J., and Hein, I. 2008. Genomic resources and tools for gene function analysis in potato. Int. J. Plant Genomics 2008:216513.

Caten, C. E., and Jinks, J. L. 1968. Spontaneous variability of single isolates of Phytophthora infestans, I. Cultural variation. Can. J. Botany 329-348.

Colton, L. M., Groza, H. I., Wielgus, S. M., and Jiang, J. M. 2006. Marker-assisted selection for the broad-spectrum potato late blight resistance conferred by gene $R B$ derived from a wild potato species. Crop Sci. 46:589-594.

Dou, D., Kale, S. D., Wang, X., Chen, Y., Wang, Q., Wang, X., Jiang, R. H., Arredondo, F. D., Anderson, R. G., Thakur, P. B., McDowell, J. M., Wang, Y., and Tyler, B. M. 2008. Conserved C-terminal motifs required for avirulence and suppression of cell death by Phytophthora sojae effector Avr1b. Plant Cell 20:1118-33.

Felsenstein, J. 1985. Confidence limits on phylogenies: An approach using the bootstrap. Evolution 39:783-791.

Flier, W. 2001. Variation in Phytophthora infestans-Sources and implications. Ph.D. Thesis Wageningen University.

Flier, W. G., Grünwald, N. J., Kroon, L., van den Bosch, T. B. M., Garay Serrano, E., Lozoya Saldana, H., Bonants, P. J. M., and Turkensteen, L. J. 2002. Phytophthora ipomoeae spp, a new homothallic species causing leaf blight on Ipomoea longipedunculata in the Toluca Valley of central Mexico. Mycological Res. 106:848-856.

Flier, W. G., Grünwald, N. J., Kroon, L., Sturbaum, A. K., van den Bosch, T. B. M., Garay Serrano, E., Lozoya Saldana, H., Fry, W. E., and Turkensteen, L. J. 2003. The population structure of Phytophthora infestans from the Toluca Valley of central Mexico suggests genetic differentiation between populations from cultivated potato and wild Solanum spp. Phytopathology 93:382-390.

Flor, H. H. 1971. Current status of the gene-for-gene concept. Ann. Rev. Phytopathol. 275-296.

Friedman, A. R., and Baker, B. J. 2007. The evolution of resistance genes in multi-protein plant resistance systems. Curr. Opin. Genet. Dev. 17:493499.

Fry, W. 2008. Phytophthora infestans: The plant (and $R$ gene) destroyer. Mol. Plant Pathol. 9:385-402.

Gouget, A., Senchou, V., Govers, F., Sanson, A., Barre, A., Rouge, P., Pont-Lezica, R., and Canut, H. 2006. Lectin receptor kinases participate in protein-protein interactions to mediate plasma membrane-cell wall adhesions in Arabidopsis. Plant Physiol. 140:81-90.

Govers, F., and Bouwmeester, K. 2008. Effector trafficking: RXLR-dEER as extra gear for delivery into plant cells. Plant Cell 20:1728-30.

Govers, F., and Gijzen, M. 2006. Phytophthora genomics: The plant destroyers' genome decoded. Mol. Plant-Microbe Interact. 19:1295-1301.

Grünwald, N. J., Flier, W. G., Sturbaum, A. K., Garay-Serrano, E., van den Bosch, T. B. M., Smart, C. D., Matuszak, J. M., Lozoya-Saldana, H., Turkensteen, L. J., and Fry, W. E. 2001. Population structure of Phytophthora infestans in the Toluca valley region of Central Mexico. Phytopathology 91:882-890.

Helgeson, J. P., Pohlman, J. D., Austin, S., Haberlach, G. T., Wielgus, S. M., Ronis, D., Zambolim, L., Tooley, P., McGrath, J. M., James, R. V., and Stevenson, W. R. 1998. Somatic hybrids between Solanum bulbocastanum and potato: A new source of resistance to late blight. Theor. Appl. Genet. 96:738-742.

Huang, S. 2005. Discovery and characterization of the major late blight resistance complex in potato: Genomic structure, functional diversity, and implications. Ph.D. thesis Wageningen University, The Netherlands

Huang, S., van der Vossen, E. A. G., Kuang, H., Vleeshouwers, V. G. A. A., Zhang, N., Borm, T. J. A., van Eck, H. J., Baker, B., Jacobsen, E., and Visser, R. G. F. 2005. Comparative genomics enabled the isolation of the $R 3 a$ late blight resistance gene in potato. Plant J.42:251-261.

Jiang, R. H., Tripathy, S., Govers, F., and Tyler, B. M. 2008. RXLR effector reservoir in two Phytophthora species is dominated by a single rapidly evolving superfamily with more than 700 members. Proc. Natl. Acad. Sci. U.S.A. 105:4874-9.

Jones, J. D., and Dangl, J. L. 2006. The plant immune system. Nature 444:323-9. 
Kamoun, S. 2006. A catalogue of the effector secretome of plant pathogenic oomycetes. Annu. Rev. Phytopathol. 44:1-20.

Kamoun, S. 2007. Groovy times: Filamentous pathogen effectors revealed. Curr. Opin. Plant Biol. 10:358-365.

Karimi, M., Inze, D., and Depicker, A. 2002. GATEWAY vectors for Agrobacterium-mediated plant transformation. Trends Plant Sci. 7:193-195.

Kramer, L. C., Choudoir, M. J., Wielgus, S. M., Bhaskar, P. B., and Jiang, J. 2009. Correlation between transcript abundance of the $R B$ gene and the level of the $R B$-mediated late blight resistance in potato. Mol. PlantMicrobe Interact. 22:447-455.

Kuang, H., Wei, F., Marano, M. R., Wirtz, U., Wang, X., Liu, J., Shum, W. P., Zaborsky, J., Tallon, L. J., Rensink, W., Lobst, S., Zhang, P., Tornqvist, C. E., Tek, A., Bamberg, J., Helgeson, J., Fry, W., You, F., Luo, M. C., Jiang, J., Robin Buell, C., and Baker, B. 2005. The R1 resistance gene cluster contains three groups of independently evolving, type I RI homologues and shows substantial structural variation among haplotypes of Solanum demissum. Plant J. 44:37-51.

Lazo, G. R., Stein, P. A., and Ludwig, R. A. 1991. A DNA transformationcompetent Arabidopsis genomic library in Agrobacterium. BioTechnology 9:963-967.

Lees, A. K., Wattier, R., Shaw, D. S., Sullivan, L., Williams, N. A., and Cooke, D. E. L. 2006. Novel microsatellite markers for the analysis of Phytophthora infestans populations. Plant Pathol. 55:311-319.

Liu, Z. Y., and Halterman, D. 2006. Identification and characterization of $R B$-orthologous genes from the late blight-resistant wild potato species Solanum verrucosum. Physiol. Mol. Plant Pathol. 69:230-239.

Naess, S. K., Bradeen, J. M., Wielgus, S. M., Haberlach, G. T., McGrath, J. M., and Helgeson, J. P. 2000. Resistance to late blight in Solanum bulbocastanum is mapped to chromosome 8. Theor. Appl. Genet. 101:697-704.

Nei, M., and Li, W. H. 1979. Mathematical model for studying genetic variation in terms of restriction endonucleases. Proc. Natl. Acad. Sci. U.S.A. 76:5269-73.

Park, T. H., Vleeshouwers, V. G. A. A., Jacobsen, E., Visser, R. G. F., and Van der Vossen, E. A. G. Molecular breeding for resistance to Phytophthora infestans in potato. Plant Breeding 128:109-117.

Pieterse, C. M., van West, P., Verbakel, H. M., Brasse, P. W., van den BergVelthuis, G. C., and Govers, F. 1994. Structure and genomic organization of the ipiB and ipiO gene clusters of Phytophthora infestans. Gene 138:67-77.

Rauscher, G. M., Smart, C. D., Simko, I., Bonierbale, M., Mayton, H., Greenland, A., and Fry, W. E. 2006. Characterization and mapping of Rpi-ber, a novel potato late blight resistance gene from Solanum berthaultii. Theor. Appl. Genet. 112:674-687.

Rehmany, A. P., Gordon, A., Rose, L. E., Allen, R. L., Armstrong, M. R., Whisson, S. C., Kamoun, S., Tyler, B. M., Birch, P. R., and Beynon, J. L. 2005. Differential recognition of highly divergent downy mildew avirulence gene alleles by $R P P 1$ resistance genes from two Arabidopsis lines. Plant Cell 17:1839-50.

Rivera-Peña, A. 1990a. Wild tuber-bearing species of Solanum and incidence of Phytophthora infestans (Mont.) de Bary on the Western slopes of the volcano Nevado de Toluca. 3. Physiological races of Phytophthora infestans. Potato Res. 33:349-355.

Rivera-Peña, A. 1990b. Wild tuber-bearing species of Solanum and incidence of Phytophthora infestans (Mont.) de Bary on the Western slopes of the volcano Nevado de Toluca. 5. Type of resistance to P. infestans. Potato Res. 33:479-486.

Rzhetsky, A., and Nei, M. 1992. A simple method for estimating and testing minimum evolution trees. Mol. Biol. Evol. 9:945-967.

Senchou, V., Weide, R., Carrasco, A., Bouyssou, H., Pont-Lezica, R. Govers, F., and Canut, H. 2004. High affinity recognition of a Phytophthora protein by Arabidopsis via an RGD motif. Cell Mol. Life Sci 61:502-9.

Song, J., Bradeen, J. M., Naess, S. K., Raasch, J. A., Wielgus, S. M., Haberlach, G. T., Liu, J., Kuang, H., Austin-Phillips, S., Buell, C. R., Helgeson, J. P., and Jiang, J. 2003. Gene RB cloned from Solanum bulbocastanum confers broad spectrum resistance to potato late blight. Proc. Natl. Acad. Sci. U.S.A. 100:9128-33.

Tamura, K., Dudley, J., Nei, M., and Kumar, S. 2007. MEGA4: Molecular Evolutionary Genetics Analysis (MEGA) software version 4.0. Mol. Biol. Evol. 24:1596-9.

Torto, T. A., Rauser, L., and Kamoun, S. 2002. The pipg1 gene of the oomycete Phytophthora infestans encodes a fungal-like endopolygalacturonase. Curr. Genet. 40:385-390.

van de Peer, Y., and de Wachter, R. 1994. TREECON for Windows: A software package for the construction and drawing of evolutionary trees for the Microsoft Windows environment. Comput. Appl. Biosci. 10:569-70. van der Fits, L., Deakin, E. A., Hoge, J. H. C., and Memelink, J. 2000. The ternary transformation system: Constitutive $\operatorname{vir} G$ on a compatible plasmid dramatically increases Agrobacterium-mediated plant transformation. Plant Mol. Biol. 43:495-502.

van der Hoorn, R. A. L., Laurent, F., Roth, R., and de Wit, P. J. G. M. 2000. Agroinfiltration is a versatile tool that facilitates comparative analyses of Avr $9 / C f 9$-induced and Avr4/Cf4-induced necrosis. Mol. Plant-Microbe Interact. 13:439-446.

van der Lee, T., de Witte, I., Drenth, A., Alfonso, C., and Govers, F. 1997. AFLP linkage map of the oomycete Phytophthora infestans. Fungal Genet. Biol. 21:278-291.

van der Vossen, E. A. G., Sikkema, A., Hekkert, B. L., Gros, J., Stevens, P., Muskens, M., Wouters, D., Pereira, A., Stiekema, W., and Allefs, S. 2003. An ancient $R$ gene from the wild potato species Solanum bulbocastanum confers broad-spectrum resistance to Phytophthora infestans in cultivated potato and tomato. Plant J. 36:867-82.

van der Vossen, E. A. G., Gros, J., Sikkema, A., Muskens, M., Wouters, D., Wolters, P., Pereira, A., and Allefs, S. 2005. The Rpi-blb2 gene from Solanum bulbocastanum is an $\mathrm{Mi}-1$ gene homolog conferring broad-spectrum late blight resistance in potato. Plant J. 44:208-22.

van Engelen, F. A., Molthoff, J. W., Conner, A. J., Nap, J. P., Pereira, A., and Stiekema, W. J. 1995. pBINPLUS: An improved plant transformation vector based on pBIN19. Transgenic Res. 4:288-290.

van Poppel, P. M. J. A., Guo, J., van de Vondervoort, P. J., Jung, M. W., Birch, P. R., Whisson, S. C., and Govers, F. 2008. The Phytophthora infestans avirulence gene Avr4 encodes an RXLR-dEER effector. Mol. Plant Microbe Interact. 21:1460-70.

van West, P., de Jong, A. J., Judelson, H. S., Emons, A. M. C., and Govers, F. 1998. The ipiO gene of Phytophthora infestans is highly expressed in invading hyphae during infection. Fungal Genet. Biol. 23:126-138.

Visser, R. G. F., Somhorst, I., Kuipers, G. J., Ruys, N. J., Feenstra, W. J. and Jacobsen, E. 1991. Inhibition of the expression of the gene for granule-bound starch synthase in potato by antisense constructs. Mol. Gen. Genet. 225:289-296.

Vleeshouwers, V. G. A. A., van Dooijeweert, W., Keizer, L. C. P., Sijpkes, L., Govers, F., and Colon, L. T. 1999. A laboratory assay for Phytophthora infestans resistance in various Solanum species reflects the field situation. Eur. J. Plant Pathol. 105:241-250.

Vleeshouwers, V. G. A. A., Rietman, H., Krenek, P., Champouret, N., Young, C., Oh, S.-K., Wang, M., Bouwmeester, K., Vosman, B., Visser, R. G. F., Jacobsen, E., Govers, F., Kamoun, S., and van der Vossen, E. A. G. 2008. Effector genomics accelerates discovery and functional profiling of potato disease resistance and Phytophthora infestans avirulence genes. PLoS ONE 3:e2875.

Wang, M., Allefs, S., van den Berg, R. G., Vleeshouwers, V. G. A. A., van der Vossen, E. A., and Vosman, B. 2008. Allele mining in Solanum: Conserved homologues of Rpi-blb1 are identified in Solanum stoloniferum. Theor. Appl. Genet. 116:933-43.

Wastie, R. 1991. Breeding for resistance. Pages 193-224. In: Phytophthora infestans, the cause of late blight of potato. D. Ingram and P. Williams, eds. Academic Press, London.

Whisson, S. C., Boevink, P. C., Moleleki, L., Avrova, A. O., Morales, J. G., Gilroy, E. M., Armstrong, M. R., Grouffaud, S., van West, P., Chapman, S., Hein, I., Toth, I. K., Pritchard, L., and Birch, P. R. J. 2007. A translocation signal for delivery of oomycete effector proteins into host plant cells. Nature 450:115-118.

Win, J., Morgan, W., Bos, J., Krasileva, K. V., Cano, L. M., ChaparroGarcia, A., Ammar, R., Staskawicz, B. J., and Kamoun, S. 2007. Adaptive evolution has targeted the C-terminal domain of the RXLR effectors of plant pathogenic oomycetes. Plant Cell 19:2349-69.

Yang, Z. 2007. PAML 4: Phylogenetic analysis by maximum likelihood. Mol. Biol. Evol. 24:1586-1591.

Yang, Z., Wong, W. S., and Nielsen, R. 2005. Bayes empirical bayes inference of amino acid sites under positive selection. Mol. Biol. Evol. 22:1107-18.

\section{AUTHOR RECOMMENDED INTERNET RESOURCES}

EUCABLIGHT, the potato late blight network for Europe: www.eucablight.org/EucaBlight.asp

Wageningen University Center of Genetic Resources (CGN) website www.cgn.wur.nl/UK/CGN+Plant+Genetic+Resources/Collections/Potato/ -+Species/ 